\title{
Process Diagnostics and Control in Thermal Spray
}

\author{
Georg Mauer $^{1}\left[\right.$ Christian Moreau $^{2}$
}

Submitted: 14 October 2021/in revised form: 6 December 2021/Accepted: 6 December 2021/Published online: 17 February 2022 (c) The Author(s) 2022

\begin{abstract}
This perspective paper summarizes the authors' view on how process diagnostics and control can help to gain a deeper insight into thermal spray processes and to better understand the underlying mechanisms. The current situation in terms of available process control strategies and suitable sensors is described. In perspective, it is assumed that with suitable models, sensors and machine learning tools, it will be possible to perform a smaller number of experiments to develop coatings with specific target characteristics. In addition, trained machine learning tools can be used to implement an efficient control strategy to produce coatings with high reproducibility and reliability. The corresponding existing knowledge gaps are analyzed to identify needs for future research.
\end{abstract}

Keywords processing, reproducibility · processing, stability of TSprocess $\cdot$ processing $\cdot$ reliability

This article is an invited paper selected to provide expert perspectives on a target subject relevant to thermal spray. The views expressed in the paper are those of the author(s). It is also part of a special issue focus in the Journal of Thermal Spray Technology celebrating the 30th anniversary of the journal. The papers and topics were curated by the Editor-in-Chief Armelle Vardelle, University of Limoges/ENSIL

Georg Mauer

g.mauer@fz-juelich.de

1 Institute of Energy and Climate Research, IEK-1: Materials Synthesis and Processing, Forschungszentrum Jülich GmbH, Jülich, Germany

2 Department of Mechanical, Industrial and Aerospace Engineering, Concordia University, Montreal, QC, Canada

\section{Introduction}

It is well known that thermal spray guns are sensitive to aging. In plasma spraying, electrodes wear results in the voltage reduction, thus in power level reduction, if the power source is operated in a constant current mode (Ref 1). In this case, it is widely practiced to increase the secondary plasma gas flow rate. In (Ref 2), time resolved diagnostic measurements of the individual particle velocities and temperatures were taken and correlated to the instantaneous voltage difference between the electrodes. The time-dependent variations in particle temperature and velocity due to the power fluctuation induced by the arc movements were found to be very large when plasma torch operates under the restrike mode $(\Delta \mathrm{P} / \mathrm{P} \approx 100 \%)$. When operating under the takeover mode, those fluctuations decrease but still remain fairly high $(\Delta \mathrm{P} / \mathrm{P} \approx 30 \%)$. Thus, the arc dynamics are a prime source of broadening the distribution of particle in-flight characteristics. As a consequence, the deposition rate and the microstructure of the sprayed coating are affected. A higher jet fluctuation thus leads to an increased porosity, a higher content of partially or not melted particles as well as to lower deposition rates (Ref 3). In (Ref 4) it was found that it is preferable to maintain the in-flight particle temperature around a constant value to obtain more consistent and reproducible deposition efficiencies and microstructures, instead of keeping a constant input power by adjusting the secondary hydrogen flow rate.

This example proves the importance of getting insight into thermal spray process and to understand the governing mechanisms. However, the matter is complex, obviously. Can process diagnostics and control help? 


\section{Current Situation}

A basis for process analyses involves schemes systemizing process variables and relations which have an impact on the coating properties. Several examples can be found in the literature, e.g., in (Ref 5-7). It must be noted that these schemes do not reflect the complexity of all effects on the coating properties in depth, e.g., stochastic, 3D, or material aspects.

Heimann et al. proposed a process structure with a threetiered hierarchy of parameters relating extrinsic ones and intrinsic ones (Ref 8). The parameters affecting the coating properties were structured as follows, first level: plasma spray system settings, second level: temperatures of plasma, particles, and substrate, and third level: particle velocity, degree of melting, and degree of bonding.

Moreau described the thermal spray processes as composed of three zones (or sub-processes). They correspond to the generation of the heat source, the heat and momentum transfer to the particles, and the coating buildup (Ref 9). Feedback strategies for process control were proposed comprising nested loops on different levels which are associated to the three process zones and their main input variables.

Another scheme was proposed by Mauer et al. (Ref 10). Here, the torch parameters, feedstock characteristics, substrate conditions, and robotic motion are designated as extrinsic operating parameters acting as input variables on the process. Monitoring of extrinsic variables can be supplemented or replaced by the observance of intrinsic ones. The latter are most influential as they are closely linked to the deposit state and bundle a variety of input parameters. Intrinsic parameters are associated with process sub-steps (Ref 11). Thus, it is apparent that the development of the torch voltage, plasma jet properties, and spray stream characteristics impact the deposit state by increasing directness the more downstream they are found in the process scheme (Ref 10).

The demand on process control strategies implies the request for appropriate sensors. Focusing on intrinsic parameters, various sensors are available to analyze the voltage fluctuation, average torch power, particle flux in the powder feedline, and in particular in-flight particle velocities and temperatures. Regarding particle diagnostic systems, since the mid-90s some sophisticated systems were developed. Some of them are even suitable for application in industrial environments (Ref 1) while others are dedicated rather to R\&D (Ref 12 ). Anyhow, the way to on-line controls with a feedback of the sensor data to the process controller was considered as long regarding the lack of knowledge on correlations between coating service properties and in-flight particle parameters (Ref 13).
It is inherent that the particle state does not fully describe the deposit formation since non-particle state parameters (feedstock flux, substrate conditions, torch motion) are not covered (Ref 14). Furthermore, it is reported that particle conditions may contain only little information on process reproducibility as they tend to be not sufficiently significant and sensitive (Ref 15). In (Ref 10), examples are given showing that T-v data can be meaningful to detect process deviation, but due to limited coverage and sensitivity not necessarily in all cases. So, a small variability in particle state was found to correspond to a large variability in coating properties (Ref 15$)$.

Another issue is that the relations between process parameters, particle in-flight properties, and coating properties may not be invertible unique (i.e., they are not oneto-one corresponding in both directions). In (Ref 16), it is shown that similar particle states can be obtained by different F4 torch parameter sets. This ambiguity complicates the establishment of closed-loop control systems based on particle diagnostics (Ref 10).

It is obvious that more data must be covered by process monitoring and capable methods are needed to interpret them appropriately. However, in thermal spray processes there are intrinsic, hidden layers of parameters and relations linking process settings, on the one hand, and coating properties, on the other hand. These complex layers are difficult to see through and thus appear as a black box. This is a typical situation to apply novel machine learning (ML) techniques. Such algorithms build models based on sample data, known as training data, in order to make predictions or decisions without being explicitly programmed to do so (Ref 17). ML is considered as a part of so-called artificial intelligence (AI). One important approach to put ML into practice is networks with layers of interconnected artificial neurons (ANN) inspired by neural networks in biological brains.

In one of the first applications of ML in thermal spraying, the effect of the plasma and powder injection parameters on particle in-flight properties (average velocity, temperature and diameter) was investigated for an $\mathrm{Al}_{2} \mathrm{O}_{3}$ feedstock with 13 wt. $\% \mathrm{TiO}_{2}$. After carrying out a validation step (to fix the ANN architecture parameters), a training step (to minimize the difference between the predicted and experimental output), and a test step (to confirm the generalization capability of the ANN), the predicted inflight characteristics were in good agreement with the measured values, in particular for particle temperatures and velocities (Ref 18, 19), in (Ref 20) for the diameters, too. In a follow-up study, also coating structural characteristics were included into the ANN. So, this model was used to investigate the oppositely directed trends of the deposition yield and the porosity (Ref 21) as well as the melting status of the particles (Ref 22). While the aforementioned studies 
focused on plasma spraying, ANN were also built for high velocity oxy-fuel spray processes (HVOF) to investigate the relations between main process parameters and particle in-flight characteristics. Here, hydroxyapatite (Ref 23) and $\mathrm{Cr}_{3} \mathrm{C}_{2}-25 \mathrm{NiCr}$ (Ref 24) feedstocks were sprayed and the effects on in-flight particle characteristics and microstructural coating properties were studied. For coatings from the latter feedstock, also the wear performance was included and predicted with good accuracy. Figure 1 shows an example for the representation of an HVOF process and the resulting coating performance by ANNs. The same group recently developed an ANN to predict the coating thickness profile of cold gas sprayed (CGS) multilayered copper coatings on flat and curved substrates with a view to additive manufacturing (Ref 25). The dependence of the critical velocity in CGS on basic feedstock characteristics was investigated by means of an ANN as well (Ref 26). For most of the investigated materials, the results were in better agreement than those obtained by an already published empirical approach. It was found that mechanical material parameters (tensile and yield strength) have the largest impact on the critical velocity followed by thermal parameters (thermal conductivity, melting temperature). The work in (Ref 27) demonstrates that ANN techniques can also be used for process monitoring. Initially, frequency bands highly contributing to the airborne acoustic emission power in HVOF were identified carrying the effects of the process parameters (powder feed rate, standoff distance). Then, the power spectra at these frequencies were used as input signals to predict the microhardness of WC-17Co coatings.

This selection of research works shows that the first steps to apply ML methods and ANN in thermal spray were done successfully. However the beginnings already go back for almost 20 years. And it is also obvious that the road is still far to models comprehensively covering the thermal spray process to the operating performance of the sprayed parts. Thus, it is of high interest to review the latest efforts in R\&D and how the user demand develops in this field.

To examine the actual status of thermal spray technology, the International Thermal Spray Conference (ITSC) is always a good opportunity. Reviewing the contributions to the ITSCs in the last years, a trend is noticeable. While the number of presentations on process diagnostics and sensors decreased, topics like ML- and AI-based approaches became permanent features of the conferences. In 2017, there was still one session "Process Diagnostics, Sensors \& Controls" with three presentations while no session or presentation was on ML. The turn came in 2018 when the first presentation on an application of AI was given in the session "Fundamentals/Research and Development". However, there was no presentation on diagnostics and sensors. In 2019, the first session on "Multi-scale Modelling and Artificial Intelligence-based Approaches" appeared in the program with three presentations while there was another session on "Diagnostics and Control" with two presentations. In 2021, one session entitled “Thermal Spray 4.0: Sensors, Data Analytics and Machine
Fig. 1 Representation of an HVOF process and the resulting coating performance by ANNs (Ref 24); reprinted with permission of Springer Nature

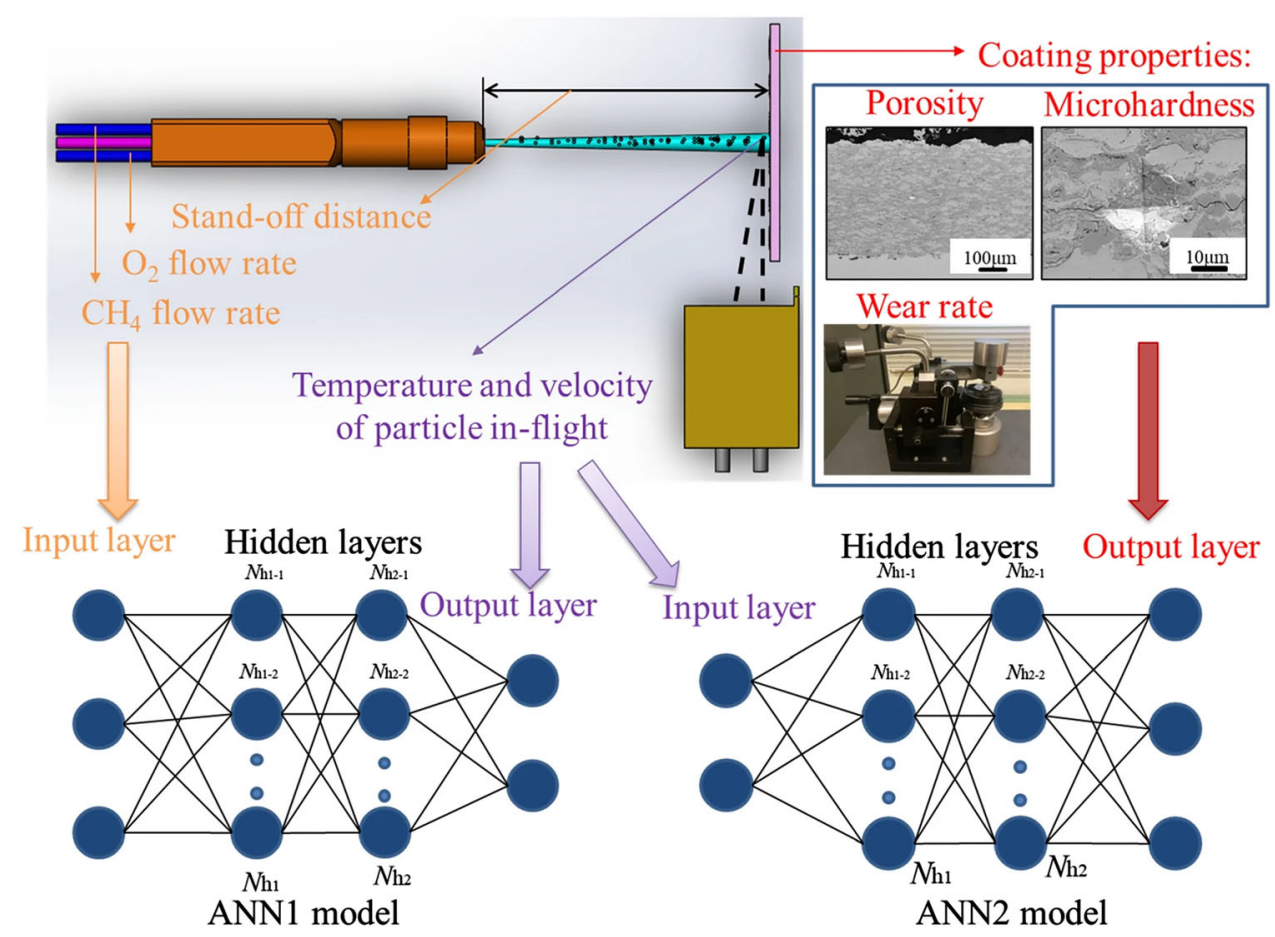


Learning" with one presentation on particle imaging and one lecture on ML were contributed. The latter was peculiar since the data to build and train the neural network did not come from experimental measurements but from calculations carried out using a validated simulation model (Ref 28).

At ITSC 2021, Dorfman (Oerlikon Metco) also gave a keynote lecture on present and future thermal spray challenges and opportunities in the aerospace industry (Ref 29) comprising several interviews with experts from business and academia. Process diagnostics and control played a major role in a number of statements. A. Ruglio (Pratt \& Whitney) criticized that until today, sensors were not fully mandated by OEMs. On the other hand, applicators would need guidance on how to implement sensors into their production and equipment suppliers should fully integrate sensors into their systems. The implementation of diagnostics had been too slow in the past. Luc Pouliot (Polycontrols) saw key factors in the development of efficient ML-based algorithms to ensure robust process control and in the improvement in sensor connectivity to follow the trends to "industry 4.0" with fully digital spraying environments. In his own statement, Dorfman confirmed the need for industrial diagnostics with closed loop data monitoring capability.

It can be concluded that process diagnostics in thermal spray are essential more than ever. They must become more intelligent and connective and well integrated in spray systems and modern production environments. In particular, novel techniques are needed to process the huge amount of measurable data and to make use of them to control thermal spray processes with respect to improved reliability and robustness. ML techniques will play a leading role to achieve this.

\section{Vision}

As pointed above, monitoring and controlling thermal spray processes are extremely challenging since these processes involve a large number of variables, some of them not being well controlled such as the electrode wear.

Sensors are important tools to monitor and eventually control spray processes but they are certainly not the only ones to achieve these functions. With the development and deployment of digital solutions in the industry, data collection, process modeling and ML will become common tools that, coupled with appropriate sensors, will make it possible to better predict spray coating characteristics and better control spray processes in production. Some ML tools such as "black box" optimization approach appears well adapted for this purpose as they do not require the formulation of an algebraic model of the process. In particular the black box approach can manage discontinuities and nonlinearities and does not require extensive computational resources (Ref 30, 31). It has already been applied to many real-world engineering problems (Ref 30). ML tools can be trained with the actual sensor data and results of numerical models, permitting the control of inflight particle characteristics and the resulting coating characteristics.

Future thermal spray production units could comprise a series of process diagnostic tools for monitoring on-line key extrinsic and intrinsic spray parameters including key coating characteristics. The control strategy will be based on properly trained ML algorithms. Such an approach should not take into account only the torch parameters and mean particle temperature and velocity. It needs to enclose a much broader view on the global spray process. For example, in plasma spraying, the mean voltage and the actual voltage fluctuation patterns will be recorded and used to feed ML algorithms. The in-flight particle characteristics should comprise not only the mean temperature and velocity but also a much comprehensive set of data including the actual distributions of the particle temperature, velocity and diameter in different points across the particle jet. Additionally, since the coating characteristics also depend on the torch movement, substrate temperature during spraying and substrate geometry, some coating characteristics can be assessed during or after spraying. For example, monitoring the coating thickness and roughness can supply key information to confirm that the properties of the coating under production meet the expected requirements. Other sensing approaches such as the In-situ Coating Property (ICP) sensor developed by Sampath and his team (Ref 14) for monitoring the residual stress and elastic modulus of the deposited coatings or optical light scattering-based techniques (Ref 32-34) can be used to assess the actual coating properties.

Beside being used for producing coatings with reproducible properties, the integration of sensors, numerical models and ML tools would make it possible to optimize much more efficiently the coating microstructure and properties for specific targeted applications. To move toward this vision, one needs to take into account not only the spray torch operation, heat and momentum transfer to the particles, robot trajectory, etc., but also the impact of the spray particles with the substrate and the resulting coating buildup. Coating buildup models based on the actual characteristics of the impacting particles and substrate will make it possible to predict key coating properties. A few limited studies have been carried out to model the growth of plasma spray (Ref 35, 36), cold spray (Ref 37), and SPS coatings (Ref 38). Again, these models coupled with data from adequate sensors can be used to train ML tools to determine the influence on spray 
parameters of the coating characteristics. Potentially, this could even reduce the efforts for microscopic inspections of metallographic cross sections.

One can foresee that, with the appropriate models, sensors and ML tools, it will be possible to conduct a reduced number of trials to engineer coatings with specific targeted characteristics (porosity level, phase content, residual stress, elastic moduli, thermal conductivity, etc.). This will make it possible to optimize the structure of the spray coatings in a more efficient way. Additionally, the trained ML tools used to optimize the coatings may be used to implement an efficient control strategy for producing the same coatings on the production floor day after day.

\section{What are the Gaps?}

We propose research priorities in three areas, sensors and testing methods, models, and machine learning (ML) to tackle the existing gaps.

\section{Sensors and Testing Methods}

The commercialization and application of sensor systems have contributed to improve the reliability of various thermal spray methodologies seriously. The precision (repeatability) of particle temperature and speed measurements is in the range of 10 Kelvin and a few meters/second, respectively, which is much smaller than the variations occurring over time due to the electrode wear as reported in (Ref 39), for example. Moreover, the drift in particle characteristics occurs typically in time intervals of several minutes while the current sensors can detect changes within a few seconds. So, the current sensors are mostly precise and rapid enough to provide reliable information for process control.

However, some emerging novel spray processes push the available sensor techniques to their limits. Thus, the understanding of the complex processes during and after liquid feedstock injection up to the layer deposition in suspension and solution precursor plasma spraying (SPS and SPPS) is incomplete so far. One major reason for this is that the available methods for process diagnostics are not sufficient (Ref 40). Moreover, it was mentioned already that small variations in particle characteristics can effect in largely varying coating characteristics.

Due to the high velocities and temperature gradients, one of the methods that can basically be considered for particle or droplet diagnostics in the plasma jet is the generation of images with high temporal and spatial resolution. For this, suitable illumination sources and filters must be used. Systems for particle diagnostics in conventional thermal spray processes, on the other hand, are not suitable because they detect only a portion of the particles, if at all (Ref 41), and cannot be used for short spray distances (Ref 42). Particle image velocimetry (PIV) is again a suitable method, since particles $<1 \mu \mathrm{m}$ can also be detected, in contrast to shadowgraphy, whose minimum resolution is only about $5 \mu \mathrm{m}$ (Ref 43). In (Ref 44), the authors analyzed the Gaussian-distributed suspension particles in the plasma jet by means of laser scattering and Mie's scattering laws. The minimum size of the suspension particles is again about $5 \mu \mathrm{m}$, since classical particle analysis methods (especially camera-based systems) reach their imaging and resolution limits here.

Due to the limited applicability of these diagnostic methods, important parameters of plasma generation, suspensions, solutions as well as injectors could hardly be optimized specifically and has been advanced mainly on empirical basis. For example, the injector systems used to date have not yet been fully developed (Ref 45). Besides SPS and SPPS, the small particle size is a particular issue also for diagnostics in aerosol deposition (AD) (Ref 46, 47) requiring solutions.

Low particle temperatures are another specific difficulty for process diagnostics in novel spray processes like CGS, high velocity air fuel spraying (HVAF), and warm spraying. Here, the thermal radiation power is too small for detection and valuation by two-color pyrometry based on Planck's law. Thus, measuring the particle thermal state during its flight and upon impact proves to be challenging. The first application of a high-speed, high-resolution infrared camera with fast readout speed to measure particle temperatures in CGS was reported in (Ref 48). This system operating in the mid-infrared spectral range $(3-5 \mu \mathrm{m})$ was used to capture in-flight temperatures of titanium particles at the exit of a CGS nozzle. The method needed to be further developed as in that work, the measured particles in the diameter range of $-150 /+45 \mu \mathrm{m}$ were still extraordinarily large and thus also slow. However, latest velocity and temperature measurements taken by another group were under realistic CGS process conditions processing Inconel 718 and $\gamma$-titanium aluminide powders (Ref 49), Fig. 2. This development must be followed up.

It is well known that the voltage fluctuations and the power level contain information about the state of the plasma torch and hence can be used for torch hardware and process monitoring (Ref 50). The signals must be measured and processed with high temporal resolution as they oscillate in the $\mathrm{kHz}$ range. In (Ref 51), e.g., a high-speed camera was used to observe the threefold plasma jet of an Axial III torch with frame rates of $2 \cdot 10^{4}$ frames per second. The images were triggered with current and voltage measurements in eight different channels at a rate of $4 \cdot 10^{7}$ samples per second. However, the available control units for plasma spray systems do not offer such possibilities. 
Present integrated trend monitors typically operate with time steps of about one second only. Hence, suitable standard interfaces in the control units of power sources for plasma spray systems to connect with high-resolution, fast monitoring systems would therefore be highly desirable.

Another kind of needed sensors is for in situ coating characteristics. First, the development of the layer thickness could be measured and controlled which is most important for 3D-shaped parts. Beyond that, the surface roughness reflects the coating deposition process and thus contains a lot of information. Besides precise and robust measurement devices, the decryption of such data requires sophisticated approaches and the identification and extraction of meaningful characteristic values.

Last but not least, the feedstocks for the novel kinetic processes at low temperatures (CGS, $\mathrm{AD}$ ) require increased attention. Here, the particle properties are of growing significance since they are no longer melted. Thus, their crystalline structure and phase composition resulting from the powder manufacturing process are not resolved and impact the coating characteristics directly. To characterize the particles, assess their sprayability, and tailor their properties, new methods are needed, e.g., micromechanical tests (Ref 52). In particular, the mechanical strength and its dependence on the particle size, which are among the most relevant properties of the feedstock powder for CGS, are rarely covered when reporting powder specifications. This is mainly due to the lack of standardized characterization methods for these specific properties (Ref 52). This problem requires concerted action by various players from research and development in academia and industry.

\section{Models}

Models are important tools to apprehend the complexity of the different thermal spray processes in terms of characteristics of the fluid flows, heat and momentum transfers,

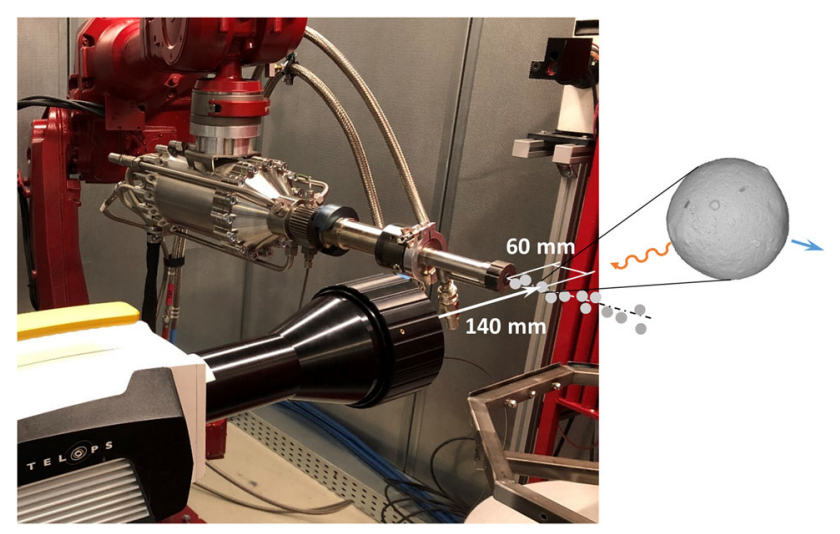

Fig. 2 High-resolution infrared camera setup for in-flight particle velocity and temperature measurements in cold gas spraying (Ref 49) phase changes, etc. To do so, better and more precise stochastic models are sought. Moreover, numerical models will further gain importance in the future as they will be used to feed ML algorithms to better control of the different spray processes. For such a use, models must be adapted to provide valuable results in a relatively short time so that numerous runs can be executed to investigate the influence of the spray parameters and their interactions.

Computation of the fluid flow fields and arc behavior in air plasma spraying has made important progress in the recent years but several additional elements need to be addressed to develop predictive models as pointed out in (Ref 53). Figure 3 shows an example of the computed plasma temperature fields obtained when two different boundary conditions are used for the magnetic vector potential in the same operation conditions of a cascaded plasma torch illustrating the difficulty in obtaining predictive results from such models. In particular, in (Ref 53), the authors identified the calculation of the voltage drop at the electrodes and a more precise description of the thermal disequilibrium at the fringes of the jet and close to the walls as necessary to improve reliability of the results. As shown in (Ref 53), such models can be used to predict the electrode wear in a cascaded plasma torch which is of high practical importance. Further work is necessary to apply such an approach to other plasma torch configurations and to better understand and predict how the wear of the electrodes actually influence the arc behavior and its fluctuations.

In the SPS and SPPS processes, the atomization of the liquid jet/droplets upon penetration in the high-temperature high-speed plasma jet, evaporation to the liquid, chemical reactions (in SPPS), fragmentation of the ceramic agglomerates and particle melting must be better modeled.

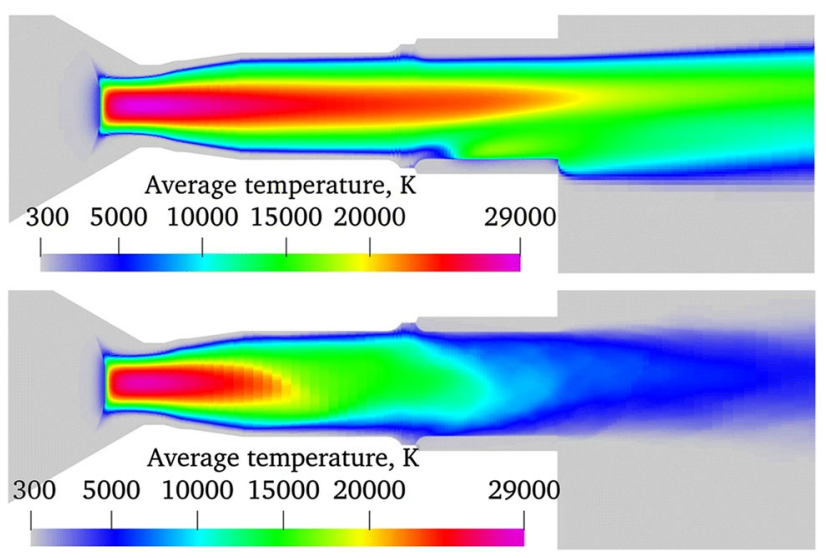

Fig. 3 Significantly different predicted time-averaged plasma temperature fields when two different boundary conditions are used for the magnetic vector potential in a cascaded plasma torch. Top image: Biot and Savart boundary conditions. Bottom image) so-called PVNF boundary conditions (Ref 53) 
All these steps influence the size of the particles and their melting state upon impact on the substrate. Each of these steps brings its own challenges in terms of predictability and computational time.

Plasma fluctuations bring an additional degree of complexity that started to be addressed but requires more attention. As described in (Ref 54, 55), very simplified models of plasma fluctuations have been used to capture the incidence of these fluctuations of the resulting particle temperature, velocity and size. Again, the predictability of the models and the computation time are still important challenges. As mentioned above, the electrode wear induces a drift in the plasma power as well as in the plasma fluctuation patterns. Such drifts in SPS and SPPS processes are expected to have a larger influence on in-flight particle characteristics than observed in APS as the transit time of the particles in the plasma jet is shorter, their speed being close to the plasma jet speed.

Being able to predict the microstructure and properties of a spray coating from the knowledge of the in-flight particle flow characteristics, torch movements, shape and roughness of the substrate and its temperature during spraying still represents a challenging task that must be addressed. The "simple" impact of a molten plasma spray droplet on a smooth substrate at room temperature is still not fully understood. When the substrate is heated at $300-400{ }^{\circ} \mathrm{C}$, droplet impact numerical models can very well predict the flattening and solidification of the impinging droplet that is in good thermal and mechanical contact with the substrate. At room temperature, when water vapor or other gases are adsorbed on the substrate surface, the spreading behavior of the droplet changes drastically. The liquid is in good contact with the substrate close to the impact location but, upon further spreading, the liquid detaches from the substrate forming a thin expanding molten film that breaks when it gets too thin. To date, no models have provided a satisfactory representation of the droplet spreading and solidification at room temperature. This is an important gap as the individual flattened and solidified droplets (usually called splats or lamellae) are the building blocks of the plasma spray coatings. The substrate temperature during spraying is also known to have a direct influence on the interlamellar pores in the spray coatings. Such pores have a strong influence of the coating properties such as thermal conductivity, elastic moduli, and strain tolerance. The liquid detachment observed at room temperature and the increased interlamellar porosity in coatings sprayed at room temperature are possibly both related to the presence of adsorbates on the impacted surface.

Similarly, modeling of particle impacts in low-temperature spray processes (cold spray, warm spray, HVAF, aerosol deposition) still need additional investigation. In the warm spray and HVAF processes, an important fraction of the particles are solid and deform plastically upon impact. Further work is necessary to identify and validate the appropriate plastic deformation model (Mie-Gruneisen Equation of State, Johnson-Cook) when the particle impacts at low temperature or near their melting point. Again, these impacting particles are the building blocks of the coatings and their characteristics directly influence the coating properties.

Coatings are built from the successive impact of particles on the substrate or already deposited layers. Modeling the actual coating buildup process has been done in plasma spray, cold spray, and other processes. Several approaches have been proposed to simulate the accumulation of particles with significant simplifications to limit the computation cost, see for example (Ref 56, 57). To be able to predict the actual coating structure and properties, one must better understand the different mechanisms involved in single particle impacts and develop stochastic computational methods that will integrate that knowledge and apply it to a number of particles large enough for well representing the deposited coatings with a reasonable computation cost.

In SPS the situation is significantly different as the main features in the coatings, the columns and cauliflowers, which have a strong influence on the coating microstructure are much larger than the micron-size spray particles (the building blocks). It is known that the columnar structure of SPS coatings results from the so-called "shadow effect" due to the deflection of the particle trajectories close to the substrate. The preliminary modeling results have shown that the substrate shape has a strong influence on the number of particles that actually land on the substrate as well as their impact angle (Ref 58). Particle properties (temperature, velocity, diameter, direction) close to the substrate surface can be used to calculate the landing position on the substrate where the particle attaches. Such an approach was used recently by Kashfi (Ref 38). Figure 4 (left) shows the set of in-flight particles with their landing position relative to the plasma torch axis. The torch was numerically scanned for several passes in front of the substrate accumulating particles one at a time. As seen in Fig. 4 (right), the resulting coating structure shows the influence of the substrate surface profile on the column size and intercolumnar gap. The initial substrate asperities are represented by the red triangles. Such approach should be further developed to better understand on how the spray parameters as well as the surface roughness and substrate shape influence the coating columnar structure.

Validation of the models discussed above also represents an important challenge that merits further attention. For example, computed in-flight particle characteristics are difficult to validate as the particle temperature and size are 

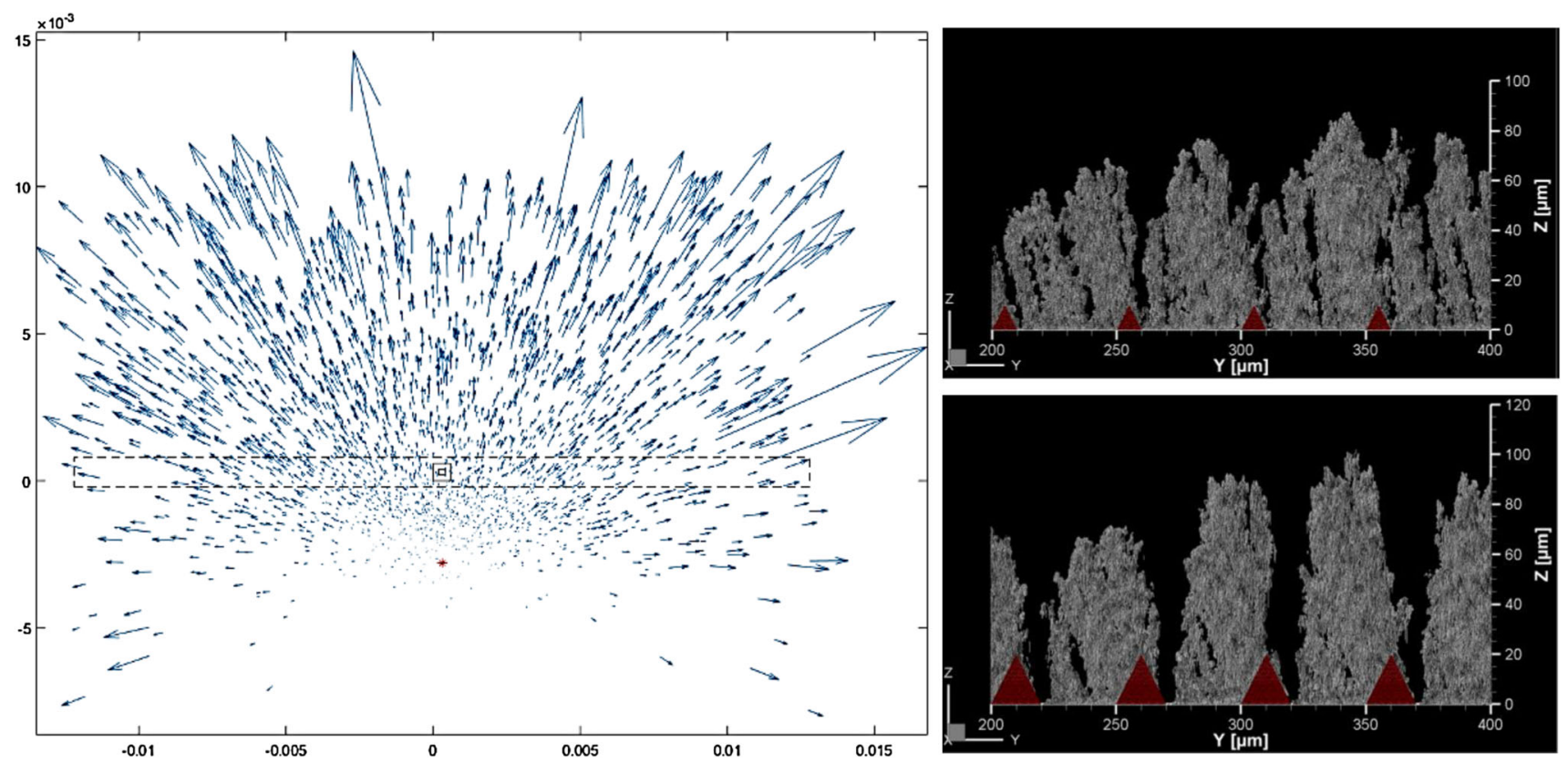

Fig. 4 Modeling of SPS coating buildup: left) particle trajectories close to the substrate surface as seen from the torch: the arrows represent the particle trajectories in the last $100 \mu \mathrm{m}$ before the

difficult to measure in SPS conditions as discussed in the previous section.

\section{Machine Learning}

Machine learning is at the heart of the fourth industrial revolution-Industry 4.0. Industrial processes can be monitored and controlled with the integration of data coming from an extensive suite of connected sensors, analyzed with innovative approaches based on artificial intelligence, machine learning and deep learning. The amount of data that can be collected and analyzed go well beyond what was possible a few years ago.

This revolution is expected to deeply transform the way the research in thermal spray is carried out and the way spray processes are controlled on the production line. ML algorithms are trained by using data collected from on-line process sensors, from coating characteristics measured onor off-line and from results of computer models. Beyond the parameters that are commonly measured today, on-line sensors can comprise measurement of voltage fluctuations at high frequency, noise in the spray booth, temperature and velocity of individual particles (not only the mean values but the whole distributions), videos of the spray process in the visible range and infrared ranges, etc. Some coating characteristics can be monitored on line such as elastic modulus, thermal conductivity, and thickness. Offline characteristics can comprise images of the coating cross sections, mapping of the coating surface, crystalline substrate surface; right) different columnar structures obtained with different sizes of substrate surface asperities (in red) (Color figure online)

phases, mechanical properties, etc. Output of the computer models discussed above can be used to determine how to adjust the spray parameters to induce a determined change in specific process or coating attributes. The strength of these artificial intelligence approaches is the possibility to learn and improve the control algorithms continuously.

As mentioned in Section 2, several studies have been initiated in the past decades to integrate neural networks for controlling thermal spray processes. However much more efforts must be dedicated in the coming years to determine the sets of data and ML approaches that are pertinent for implementing robust control strategies for developing optimum coatings and for controlling thermal spray processes in industrial production.

\section{Final Statement}

For process control, monitoring parameters which are sensitive and representative for coating quality are a key issue of every approach to improve process reliability. Besides the development of sensors and tests, the involvement of models can contribute to reduce experimental efforts and to build large databases. Machine learning approaches will help to exploit these resources effectively and to control process conditions. Despite the great importance of diagnostics for control, it is important to remember that coating properties depend on numerous parameters, which are not necessarily all covered (Ref 59). 
Process design is closely related to process control since also here process parameters must be identified to achieve specific coating properties. It must be provided that the underlying relations are invertible unique (Ref 10). Since the complexity of these relations often exceeds our knowledge and understanding, process design will also benefit from the mentioned developments in the field of sensors and test methods, models and machine learning systems.

The further development of sensors, testing, modeling, and machine learning techniques is found in concerted action with other activities to improve the design and control of thermal spray processes. Examples include the development of stable equipment such as cascaded plasma torches or the production of precursors in compliance with increasingly tight specifications.

Despite all the enthusiasm about expanded technical possibilities, it must not be forgotten that also the practical knowledge of well-trained personnel is an important resource for process diagnostics and control now and in the future. Hence, effective methods for collection, systematization, representation and transfer of knowledge will be important, which admittedly goes beyond the thematic scope of this article.

Funding Open Access funding enabled and organized by Projekt DEAL.

Open Access This article is licensed under a Creative Commons Attribution 4.0 International License, which permits use, sharing, adaptation, distribution and reproduction in any medium or format, as long as you give appropriate credit to the original author(s) and the source, provide a link to the Creative Commons licence, and indicate if changes were made. The images or other third party material in this article are included in the article's Creative Commons licence, unless indicated otherwise in a credit line to the material. If material is not included in the article's Creative Commons licence and your intended use is not permitted by statutory regulation or exceeds the permitted use, you will need to obtain permission directly from the copyright holder. To view a copy of this licence, visit http://creativecommons. org/licenses/by/4.0/.

\section{References}

1. P. Fauchais and M. Vardelle, Sensors in Spray Processes, $J$. Therm. Spray Technol., 2010, 19(4), p 668-694.

2. J.F. Bisson, B. Gauthier and C. Moreau, Effect of Plasma Fluctuations on In-Flight Particle Parameters, J. Therm. Spray Technol., 2003, 12(1), p 38-43.

3. J.F. Bisson and C. Moreau, Effect of Direct-Current Plasma Fluctuations on In-Flight Particle Parameters: Part II, J. Therm. Spray Technol., 2003, 12(2), p 258-264.

4. J.F. Bisson, C. Moreau, M. Dorfman, C. Dambra and J. Mallon, Influence of Hydrogen on the Microstructure of Plasma-Sprayed Yttria-Stabilized Zirconia Coatings, J. Therm. Spray Technol., 2005, 14(1), p 85-90.

5. M. Friis, C. Persson, Process Window for Plasma Spray Processes, Thermal Spray 2001: New Surfaces for a New
Millennium, C.C. Berndt, K.A. Khor, E. Lugscheider Eds., May 28-30, 2001 (Singapore), ASM International

6. R.B. Heimann, Plasma spray coating : principles and applications, $2^{\text {nd }}$ ed., Wiley-VCH, 2008

7. P. Fauchais, M. Vardelle and A. Vardelle, Reliability of PlasmaSprayed Coatings: Monitoring the Plasma Spray Process and Improving the Quality of Coatings, J. Phys. D: Appl. Phys., 2013, 46(22), p 224016.

8. R.B. Heimann, D. Lamy and T. Sopkow, Optimization of Vacuum Plasma Arc Spray Parameters of 88WC12Co Alloy Coatings Using a Statistical Multifactorial Design Matrix, J. Can. Ceram. Soc., 1990, 59(3), p 49-54.

9. C. Moreau, Towards a better control of thermal spray processes, Thermal Spray 1998: Meeting the Challenges of the $21^{\text {st }}$ Century, Proceedings of the $15^{\text {th }}$ International Thermal Spray Conference, C. Coddet Ed., May 25-29, 1998 (Nice, France), ASM International, 1998, pp 1681-1693

10. G. Mauer, K.-H. Rauwald, R. Mücke and R. Vaßen, Improved Reliability and Specific Design of Plasma Spray Processes, $J$. Therm. Spray Technol., 2017, 26(5), p 799-810.

11. G. Dwivedi, T. Wentz, S. Sampath and T. Nakamura, Assessing Process and Coating Reliability Through Monitoring of Process and Design Relevant Coating Properties, J. Therm. Spray Technol., 2010, 19(4), p 695-712.

12. K. Landes, Diagnostics in Plasma Spraying Techniques, Surf. Coat. Technol., 2006, 201(5), p 1948-1954.

13. J.F. Coudert, M. Vardelle and P. Fauchais, Diagnostics of Plasma Spray Process and Derived On-Line Control, High Temp. Mater. Process., 2002, 6(2), p 19.

14. S. Sampath, V. Srinivasan, A. Valarezo, A. Vaidya and T. Streibl, Sensing, Control, and In Situ Measurement of Coating Properties: An Integrated Approach Toward Establishing Process-Property Correlations, J. Therm. Spray Technol., 2009, 18(2), p 243-255.

15. V. Srinivasan, S. Sampath, A. Vaidya, T. Streibl and M. Friis, On the Reproducibility of Air Plasma Spray Process and Control of Particle State, J. Therm. Spray Technol., 2006, 15(4), p 739-743.

16. J. Colmenares-Angulo, K. Shinoda, T. Wentz, W. Zhang, Y. Tan and S. Sampath, On the Response of Different Particle State Sensors to Deliberate Process Variations, J. Therm. Spray Technol., 2011, 20(5), p 1035-1048.

17. J.R. Koza, F.H. Bennett, D. Andre, M.A. Keane, Automated Design of Both the Topology and Sizing of Analog Electrical Circuits Using Genetic Programming, Artificial Intelligence in Design '96, J.S. Gero, F. Sudweeks, Eds., Springer Netherlands, 1996, p 151-170

18. S. Guessasma, G. Montavon, P. Gougeon and C. Coddet, Designing Expert System Using Neural Computation in View of the Control of Plasma Spray Processes, Mater. Des., 2003, 24(7), p 497-502.

19. S. Guessasma, Z. Salhi, G. Montavon, P. Gougeon, C. Coddet, Artificial Intelligence Implementation in the APS Process Diagnostic. Mater. Sci. Eng, B, 2004, 110(3):285-295

20. T.A. Choudhury, N. Hosseinzadeh and C.C. Berndt, Artificial Neural Network Application for Predicting In-Flight Particle Characteristics of an Atmospheric Plasma Spray Process, Surf. Coat. Technol., 2011, 205(21), p 4886-4895.

21. A.-F. Kanta, G. Montavon, M.-P. Planche and C. Coddet, Artificial Neural Networks Implementation in Plasma Spray Process: Prediction of Power Parameters and In-Flight Particle Characteristics vs. Desired Coating Structural Attributes, Surf. Coat. Technol., 2009, 203(22), p 3361-3369.

22. A.F. Kanta, M.P. Planche, G. Montavon and C. Coddet, In-Flight and Upon Impact Particle Characteristics Modelling in Plasma Spray Process, Surf. Coat. Technol., 2010, 204(9), p 1542-1548.

23. M. Liu, Z. Yu, C. Chen, H. Liao, S. Deng, Analysis and Optimization of the HVOF Process by Artificial Neural Networks 
Model, Thermal Spray 2018: Proceedings of the International Thermal Spray Conference, F. Azarmi, K. Balani, T. Eden, T. Hussain, Y.-C. Lau, H. Li, K. Shinoda, F.-L. Toma, J. Veilleux Eds., May 7-10, 2018 (Orlando, FL), ASM International, 2018, pp 330-336

24. M. Liu, Z. Yu, H. Wu, H. Liao, Q. Zhu and S. Deng, Implementation of Artificial Neural Networks for Forecasting the HVOF Spray Process and HVOF Sprayed Coatings, J. Therm. Spray Technol., 2021, 30(5), p 1329-1343.

25. M. Liu, H. Wu, Z. Yu, H. Liao and S. Deng, Description and Prediction of Multi-layer Profile in Cold Spray Using Artificial Neural Networks, J. Therm. Spray Technol., 2021, 30(6), p 1453-1463.

26. Z. Wang, S. Cai, W. Chen, R.A. Ali and K. Jin, Analysis of Critical Velocity of Cold Spray Based on Machine Learning Method with Feature Selection, J. Therm. Spray Technol., 2021, 30(5), p 1213-1225.

27. S. Kamnis, K. Malamousi, A. Marrs, B. Allcock and K. Delibasis, Aeroacoustics and Artificial Neural Network Modeling of Airborne Acoustic Emissions During High Kinetic Energy Thermal Spraying, J. Therm. Spray Technol., 2019, 28(5), p 946-962.

28. K. Bobzin, W. Wietheger, H. Heinemann, S.R. Dokhanchi, M. Rom and G. Visconti, Prediction of Particle Properties in Plasma Spraying Based on Machine Learning, J. Therm. Spray Technol., 2021, 30(7), p 1751-1764. https://doi.org/10.1007/s11666-021$01239-2$

29. M.R. Dorfman, Present and Future Thermal Spray Challenges and Opportunities in the Aerospace Industry, International Thermal Spray Conference 2021: Versatile Surface Engineering for Environmental Solutions, May 24-28, 2021 (Virtual event), ASM International, 2021

30. C. Audet, A Survey on Direct Search Methods for Blackbox Optimization and Their Applications, Mathematics Without Boundaries: Surveys in Interdisciplinary Research, P.M. Pardalos, T.M. Rassias, Eds., Springer New York, 2014, p 31-56

31. C. Audet and W. Hare, Derivative-Free and Blackbox Optimization, Springer, 2017.

32. D. Stifter, Beyond Biomedicine: A Review of Alternative Applications and Developments for Optical Coherence Tomography, Appl. Phys. B: Lasers Opt., 2007, 88(3), p 337-357.

33. W.A. Ellingson, R.J. Visher, R.S. Lipanovich and C.M. Deemer, Optical NDE Methods for Ceramic Thermal Barrier Coatings, Mater. Eval., 2006, 64(1), p 52-60.

34. J. Veilleux, C. Moreau, D. Lévesque, M. Dufour and M. Boulos, Optical Coherence Tomography for the Inspection of PlasmaSprayed Ceramic Coatings, J. Therm. Spray Technol., 2007, 16(3), p 435-443.

35. M. Xue, S. Chandra, J. Mostaghimi and C. Moreau, A Stochastic Coating Model to Predict the Microstructure of Plasma Sprayed Zirconia Coatings, Model. Simul. Mater. Sci. Eng., 2008, 16(6), p 065006.

36. J. Mostaghimi, S. Chandra, R. Ghafouri-Azar and A. Dolatabadi, Modeling Thermal Spray Coating Processes: A Powerful Tool in Design and Optimization, Surf. Coat. Technol., 2003, 163-164, p 1-11.

37. F. Delloro, M. Jeandin, D. Jeulin, H. Proudhon, M. Faessel, L. Bianchi, E. Meillot and L. Helfen, A Morphological Approach to the Modeling of the Cold Spray Process, J. Therm. Spray Technol., 2017, 26(8), p 1838-1850.

38. B. Kashfi Ashtiani, Development of a Three-Dimensional Suspension Plasma Spray Coating Build-up Model, Masters thesis, Concordia University, 2020

39. L. Leblanc and C. Moreau, The Long-Term Stability of Plasma Spraying, J. Therm. Spray Technol., 2002, 11(3), p 380-386.
40. P. Fauchais, M. Vardelle, S. Goutier and A. Vardelle, Key Challenges and Opportunities in Suspension and Solution Plasma Spraying, Plasma Chem. Plasma Process., 2015, 35(3), p 511-525.

41. J.-K. Lee, S.-J. Park, Y.-S. Oh, S. Kim, H. Kim and S.-M. Lee, Fragmentation Behavior of $\mathrm{Y}_{2} \mathrm{O}_{3}$ Suspension in Axially Fed Suspension Plasma Spray, Surf. Coat. Technol., 2017, 309, p 456-461.

42. J. Oberste Berghaus and B.R. Marple, High-Velocity Oxy-Fuel (HVOF) Suspension Spraying of Mullite Coatings, J. Therm. Spray Technol., 2008, 17(5), p 671-678.

43. P. Fauchais, M. Vardelle, S. Goutier and A. Vardelle, Specific Measurements of In-Flight Droplet and Particle Behavior and Coating Microstructure in Suspension and Solution Plasma Spraying, J. Therm. Spray Technol., 2015, 24(8), p 1498-1505.

44. A. Akbarnozari, S. Amiri, A. Dolatabadi and C. Moreau, Analysis of Scattering Light from In-flight Particles in Suspension Plasma Spray for Size Measurement, J. Therm. Spray Technol., 2019, 28(4), p 678-689.

45. P. Fauchais, M. Vardelle, A. Vardelle and S. Goutier, What Do We Know, What are the Current Limitations of Suspension Plasma Spraying?, J. Therm. Spray Technol., 2015, 24(7), p 1120-1129.

46. J. Akedo, Aerosol Deposition of Ceramic Thick Films at Room Temperature: Densification Mechanism of Ceramic Layers, $J$. Am. Ceram. Soc., 2006, 89(6), p 1834-1839.

47. J. Akedo, Room Temperature Impact Consolidation (RTIC) of Fine Ceramic Powder by Aerosol Deposition Method and Applications to Microdevices, J. Therm. Spray Technol., 2008, 17(2), p 181-198.

48. A. Nastic and B. Jodoin, Evaluation of Heat Transfer Transport Coefficient for Cold Spray Through Computational Fluid Dynamics and Particle In-Flight Temperature Measurement Using a High-Speed IR Camera, J. Therm. Spray Technol., 2018, 27(8), p 1491-1517.

49. J. Fiebig, J.-P. Gagnon, G. Mauer, E. Bakan, R. Vaßen, In-flight measurements of particle temperature and velocity with a highspeed IR-Camera during cold gas spraying of IN718 and TiAlCrNb, J. Therm. Spray Technol., 2022, under review

50. G. Mauer, J.-L. Marqués-López, R. Vaßen and D. Stöver, Detection of Wear in One-Cathode Plasma Torch Electrodes and its Impact on Velocity and Temperature of Injected Particles, $J$. Therm. Spray Technol., 2007, 16(5-6), p 933-939.

51. S. Zimmermann, G. Mauer, K.-H. Rauwald and J. Schein, Characterization of an Axial-Injection Plasma Spray Torch, $J$. Therm. Spray Technol., 2021, 30(7), p 1724-1736.

52. H. Assadi and F. Gärtner, Particle Compression Test: A Key Step towards Tailoring of Feedstock Powder for Cold Spraying, Coatings, 2020, 10(5), p 458.

53. R. Zhukovskii, C. Chazelas, A. Vardelle, V. Rat and B. Distler, Effect of Electromagnetic Boundary Conditions on Reliability of Plasma Torch Models, J. Therm. Spray Technol., 2020, 29(5), p 894-907.

54. E. Dalir, C. Moreau and A. Dolatabadi, Three-Dimensional Modeling of Suspension Plasma Spraying with Arc Voltage Fluctuations, J. Therm. Spray Technol., 2018, 27(8), p 1465-1490.

55. E. Meillot, D. Guenadou and C. Bourgeois, Three-Dimension and Transient D.C. Plasma Flow Modeling, Plasma Chem. Plasma Process., 2008, 28(1), p 69-84.

56. R. Ghafouri-Azar, J. Mostaghimi, S. Chandra and M. Charmchi, A Stochastic Model to Simulate the Formation of a Thermal Spray Coating, J. Therm. Spray Technol., 2003, 12(1), p 53-69.

57. S. Bhusal, C. Zhang, J. Bustillos, P. Nautiyal, B. Boesl and A. Agarwal, A Computational Approach for Predicting 
Microstructure and Mechanical Properties of Plasma Sprayed Ceramic Coatings from Powder to Bulk, Surf. Coat. Technol., 2019, 374, p 1-11.

58. K. Pourang, C. Moreau and A. Dolatabadi, Effect of Substrate and Its Shape on in-Flight Particle Characteristics in Suspension Plasma Spraying, J. Therm. Spray Technol., 2016, 25(1-2), p 44-54.
59. P.L. Fauchais, J.V.R. Heberlein and M.I. Boulos, Thermal Spray Fundamentals: From Powder to Part, Springer, 2014.

Publisher's Note Springer Nature remains neutral with regard to jurisdictional claims in published maps and institutional affiliations. 